\section{Commentary: Looking for certainties, finding uncertainties}

\author{
Fabio Barili, MD, PhD, FESC, ${ }^{\mathrm{a}}$ and \\ Alessandro Parolari, $\mathrm{MD}, \mathrm{PhD}^{\mathrm{b}}$
}

Statistical analysis for clinicians is essentially a tool intended to help address clinical questions, make decisions, and guarantee the best treatment for every single patient. This scope is challenging, because the truth is not always easy to find, if there is one, and we face several specific difficulties, such as evolution of techniques, differences in expertise, and lack of equipoise, not only in surgery as a field of research, but also in clinical research itself.

In this issue of the Journal, Gaudino and colleagues ${ }^{1}$ shed light on the pros and cons of design and methods for clinical studies without sparing criticisms of randomized clinical trials. This is a keystone note, as it claims the potential misunderstanding of uncritical faith in statistical methods in search of the "truth." They are only tools, useful but not infallible by their nature, dependent on the human factor more than on their intrinsic limitations.

The exponential growth of scientific literature is not necessarily related to a growth in quality of evidence, and the phenomenon of "publish or perish" ${ }^{2}$ has resulted in misuse of statistical analysis for limited knowledge, among other consequences. The availability of more and more simple statistical programs for one-click analysis has increased the responsibility to choose the more adequate method and critically interpreting results to avoid biased conclusions. For example, the assumption of hazards proportionality of a simple Cox model, which in other words means accepting or refusing it (if results are reliable or unusable), is often not checked, and the software gives the output regardless of its validity, demanding the model's acceptance to the researcher. Balancing methods for observational and retrospective studies have become very popular in cardiovascular medicine,

\footnotetext{
From the ${ }^{\mathrm{a} D e p a r t m e n t}$ of Cardiac Surgery, Santa Croce Hospital, Cuneo, Italy; and ${ }^{\mathrm{b}}$ Cardiac Surgery Department, IRCCS Policlinico San Donato, San Donato Milanese, Italy.

Disclosures: The authors reported no conflicts of interest.

The Journal policy requires editors and reviewers to disclose conflicts of interest and to decline handling or reviewing manuscripts for which they may have a conflict of interest. The editors and reviewers of this article have no conflicts of interest.

Received for publication Dec 1, 2020; revisions received Dec 1, 2020; accepted for publication Dec 2, 2020; available ahead of print Dec 9, 2020.

Address for reprints: Fabio Barili, MD, PhD, FESC, Department of Cardiac Surgery, S Croce Hospital, via M. Coppino 26, 12100 Cuneo, Italy (E-mail: fabarili@ libero.it or barili.f@ospedale.cuneo.it).

J Thorac Cardiovasc Surg 2022;163:763

$0022-5223 / \$ 36.00$

Copyright (C) 2020 by The American Association for Thoracic Surgery

https://doi.org/10.1016/j.jtcvs.2020.12.007
}

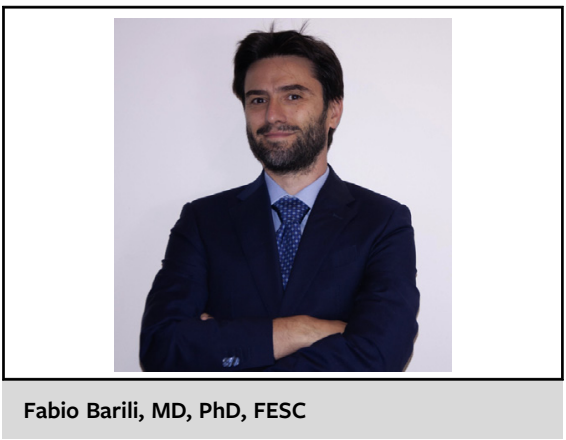

CENTRAL MESSAGE

This expert opinion is a valuable tool for interpreting pros and cons of clinical study designs, demystifying the illusive search for the source of the truth.

and their rightful use cannot be prescinded by knowledge of the assumption of ignorability, propensity score misspecification, and confounding by indication, which could lead to the ultimate decision: balance cannot be fairly obtained, and the study cannot be performed. ${ }^{3}$ More attention should be given to randomized clinical trials (RCTs), because greater importance leads to greater responsibility. RCTs are not the panacea of all diseases for clinical research and have different meanings and applications than observational studies, together with advantages and limitations. Misuse of composite outcomes for the sake of economic reasons, as well as the potential biases related to sponsorships, are some potential drawbacks of RCTs that researchers should be aware of. ${ }^{4,5}$

This expert opinion is a valuable tool for interpreting pros and cons of clinical study designs, demystifying the illusive search for the source of the truth. At the end, we agree, the more reliable truth emerges from a balance of approaches and thoughts.

\section{References}

1. Gaudino M, Bagiella E, Chang HL, Kurlansky P. Randomized trials, observational studies, and the illusive search for the source of truth. J Thorac Cardiovasc Surg. 2022; 163:757-62.

2. D'Souza DM, Sade RM, Moffatt-Bruce SD. The many facets of research integrity: what can we do to ensure it? J Thorac Cardiovasc Surg. 2020;160:730-3.

3. Barili F, Freemantle N, Folliguet T, Muneretto C, De Bonis M, Czerny M, et al The flaws in the detail of an observational study on transcatheter aortic valve implantation versus surgical aortic valve replacement in intermediate-risks patients. Eur J Cardiothorac Surg. 2017;51:1031-5.

4. Ridker PM, Torres J. Reported outcomes in major cardiovascular clinical trials funded by for-profit and not-for-profit organizations: 2000-2005. JAMA. 2006;295:2270-4.

5. Freemantle N, Calvert M, Wood J, Eastaugh J, Griffin C. Composite outcomes in randomized trials: greater precision but with greater uncertainty? JAMA. 2003; 289:2554-9. 